\title{
AC 2009-236: DEVELOPMENT OF COURSE-ASSESSMENT METRICS TO MEASURE PROGRAM OUTCOMES AGAINST ABET CRITERIA IN A DIGITAL CIRCUITS CLASS
}

\author{
Min-Sung Koh, Eastern Washington University
}

\section{Esteban Rodriguez-Marek, Eastern Washington University}

ESTEBAN RODRIGUEZ-MAREK is an Associate Professor in the department of Engineering and Design at Eastern Washington University. He did his graduate work in Electrical Engineering at Washington State University. He worked as a research scientist at Fast Search \& Transfer before transferring to the Department of Engineering \& Design at Eastern Washington University. His interest include image and video processing, communication systems, digital signal processing, and cryptographic theory and applications.

\section{Claudio Talarico, Eastern Washington University}

Claudio Talarico is an Assistant Professor of Electrical Engineering at Eastern Washington University. Before joining Eastern Washington University, he worked at University of Arizona, University of Hawaii and in industry, where he held both engineering and management positions at Infineon Technologies, IKOS Systems (now Mentor Graphics), and Marconi Communications. His research interests include design methodologies for integrated circuits and systems with emphasis on system-level design, embedded systems, HW/SW co-design, system specification languages, and early design assessment, analysis, and refinement of complex SOCs. Talarico received a PhD in electrical engineering form the University of Hawaii at Manoa, and is a member of IEEE. Contact him at ctalarico@ewu.edu 


\title{
Development of Course Assessment Metrics to Measure Program Outcomes Against ABET Criteria in a Digital Circuits Class
}

\author{
Min-Sung Koh, Esteban Rodriguez-Marek, and Claudio Talarico \\ School of Computing and Engineering Sciences \\ Eastern Washington University \\ Cheney, Washington 99004 \\ USA \\ Email: \{mkoh, erodriguezma, ctalarico\}@ewu.edu
}

\begin{abstract}
The Accreditation Board for Engineering and Technology (ABET) [5] documentation lists all essential criteria for Engineering Technology and Engineering programs to obtain pertinent accreditation. However, ABET does not specify any methodology or rubric on how to appropriately determine when achievement of a criterion has been met. Hence, each individual Engineering Technology and Engineering program must establish its own program objectives and corresponding program outcomes, ensuring coverage of all ABET criteria. Then, each program must establish a systematic way of demonstrating that its objectives and outcomes are being met, therefore meeting the ABET criteria as well. One way of doing this is incorporating the assessment into various (or all) courses in the program, a process tested and introduced by the authors in [1]. In that paper a holistic approach was used to meet ABET criteria based on course assessment. However, the details on how to exactly incorporate assessment into each course were omitted. In this paper, we describe the process followed to generate assessment data from a Digital Circuits introductory course. These data connects course objectives into program outcomes based on the approach introduced in [1]. The paper shows how traditional student work, such as homework, exams, labs, quizzes, and projects, is used systematically to provide a solid framework for assessment and continuous improvement. Further, the data is used for meeting ABET criteria.
\end{abstract}

\section{Introduction}

An intrinsic part of the ABET accreditation process requires programs to assess whether all specified ABET criteria are being evaluated, addressed and included in a continuous improvement loop. However, ABET does not provide any standardized program assessment method to determine what is an adequate "number" to receive accreditation. Hence, the process to establish a proper program assessment system is an important and difficult one. Many pedagogical research addressing program assessment for ABET criteria have been introduced in [2],[3],[4], and [7] to name a few. One program assessment method, which can be done using automatic data processing, was introduced by the authors in [1]. This process was originally motivated by the ABET accreditation team visit, a few years back, for the Computer Engineering Technology (CET) program 
and it was based on the program assessment at Purdue university introduced in [6] and [7]. Since then, the implementation of the program assessment has been adjusted and revised to improve the assessment process and to incorporate various course assessment tools. In this paper, detail course assessment metrics omitted in the program assessment paper [1] are explained. Notice that all revised and improved course assessment metrics in this paper are incorporated into the program assessment method explained in [1]. Furthermore, all detailed course assessment metrics introduced in this paper were tested in the CET program evaluation for ABET accreditation at Eastern Washington University in 2008.

In brief, course assessment metrics introduced in this paper are divided into two parts, one done by the instructor, and one done by the students in all classes in the program. The instructor uses traditional assignments such as homeworks, labs, exams, quizzes, and projects etc. However, each assignment is segmented into small pieces mapped into respective course learning objectives. This partitioning results in very accurate and relevant metric for each one of the course learning objectives. Student input for each class is done through a survey, which is designed to have a one-to-one mapping with the course learning objectives. The evaluations are combined to evaluate all course objectives in a particular class. Note that once these data are input by the instructor into the assessment tool described in [1], the rest of the measurements are automatically generated. As this process is very important, the mapping from course objectives into ABET criteria explained in [1] is summarized briefly in section 2. The process by which class assessments uses course objectives' data to measure achievement of ABET criteria is introduced in sections 3 and 4. Conclusions follow in section 5.

\section{Course objectives from ABET criteria}

The ABET Technology Accreditation Commission (TAC) criteria a-k for program outcomes in [5] are broadly defined to include various engineering technology fields. The expectation is that each program must establish specific outcomes, based on the given criteria $\mathrm{a}-\mathrm{k}$, but also addressing the respective vision and mission of the Department, College, and University. Our CET program established several outcomes (listed in Table 1) based on the ones provided by ABET.

The outcomes shown in Table 1 have been mapped to related ABET program outcome criteria a-k (shown using Table 1 in [1]). Through this mapping, ABET criteria a-k are changed into tangible requirements for each program. These program outcomes are further distributed into various (or all, as done in our institution) courses of a program so that the combination of the measurements of all classes in a program can be used to demonstrate satisfactory achievement of ABET criteria. To achieve the established program outcomes in Table 1, course learning objectives of each class were matched to one (or more) corresponding program outcomes. All relationships from course objectives to ABET program outcome criteria a-k are combined into a standardized 4-pages course evaluation Excel sheets shown in Appendix A, B, C, and D. Every class in the curriculum has a similar 4 pages spreadsheet used for assessment. The course assessment given in 
Appendix A is fundamentally divided into the two parts mentioned above. The instructor component is explained in Section 3 and the student portion in Section 4.

1.1 Students will demonstrate their ability to understand technical and industrial terminology and processes.

1.2 Students will demonstrate their ability to understand industrial concepts.

1.3 Students will demonstrate their ability to apply learned knowledge to practical problems and adapt to emerging applications of mathematics, science, engineering and technology.

1.4 Students will demonstrate proficiency in the use of typical tools, hardware, and software in an efficient manner.

1.5 Students will demonstrate proficiency in conducting, analyzing, and interpreting experiments; and applying experimental results to improve processes.

1.6 Students will demonstrate their ability to evaluate a problem and bring general design strategies to bear on the problem with a commitment to quality, timeliness, and continuous improvement.

1.7 Students will demonstrate their ability to plan and coordinate a project and manage systems.

2.1 Students will demonstrate their ability to function effectively in teams.

2.2 Students will demonstrate understanding of professional ethical and social responsibilities, within a context of contemporary professional, societal and global issues.

2.3 Students will demonstrate the ability to engage in lifelong learning.

2.4 Students will demonstrate the ability to write clearly and concisely to a variety of audiences.

2.5 Students will demonstrate proficiency in communicating verbally, giving presentations, listening to and considering diverging points of view.

3.1 Students will have an active role in professional societies.

\section{Table 1. Outcomes for CET program}

As a case study, the course objectives of "Digital Circuits" for freshman are shown in the first column of Figure 1. Notice that Figure 1 is extracted from the standardized course evaluation Excel spreadsheet for instructor's evaluation (shown completely in Appendix A). The program outcomes corresponding to each course objective are listed on the third column of the figure. Furthermore, ABET criteria corresponding to our program outcomes are listed on the second column. Hence, course objectives in each class are mapped all the way up into ABET criteria. For instance, it is shown that the course objective \#4, "Describe the operation of each type of basic logic gate", corresponds to ABET criteria "a" and "b" and those two ABET criteria are mapped into our program outcomes 1.1, 1.2, 1.3, and 1.4 in Table 1. Thus, the first three columns in Figure 1 provide the complete interconnection between course learning objectives, program outcomes, and ABET criteria a-k. All details of Excel sheets are shown in Appendix A D. Note that a similar spreadsheet is used across the board in every course in the curriculum, thereby standardizing course assessment. Metrics shown in other columns in Figure 1 used to measure each course objective, are explained in the next section. The last column in Figure 1, labeled "Perf. Comp" (i.e. a composite of student performance), 
provides the average of all measurements, normalized into a GPA-like score from 0.0 to 4.0. This score is used throughout all the paper (and assessment process).

\begin{tabular}{|c|c|c|c|c|c|c|c|c|c|c|c|c|c|c|c|}
\hline \multirow[b]{3}{*}{ Course Objective } & & & \multicolumn{13}{|c|}{ Engr 160 - Digital Logic: Instructor and Student Course Objective Assessment } \\
\hline & \multicolumn{2}{|c|}{ Fall 2008} & & \multicolumn{6}{|c|}{ Instructor: Rodriguez-Marek } & & & & & & \\
\hline & \begin{tabular}{|c|} 
Suppor \\
ted \\
Criterio \\
$n$
\end{tabular} & $\begin{array}{l}\text { Supprt'd } \\
\text { Related } \\
\text { Outcome }\end{array}$ & \begin{tabular}{|c|} 
Assm \\
nt \\
Tool \\
1 \\
\end{tabular} & $\begin{array}{c}\text { Scor } \\
\mathrm{e} \\
{[\%]}\end{array}$ & \begin{tabular}{|c|} 
Cou \\
Assm \\
nt \\
Tool \\
2 \\
\end{tabular} & \begin{tabular}{|c|} 
Ise Em \\
Scor \\
e \\
(\%)
\end{tabular} & \begin{tabular}{|c|} 
nbedded \\
Assm \\
nt \\
Tool \\
3 \\
\end{tabular} & \begin{tabular}{|l|} 
Asse \\
Scor \\
$e$ \\
$(\%)$ \\
\end{tabular} & \begin{tabular}{|c|} 
essmen \\
Assm \\
nt \\
Tool \\
4 \\
\end{tabular} & \begin{tabular}{|c|} 
Scor \\
St \\
e \\
$\%]$
\end{tabular} & \begin{tabular}{|c|} 
Assm \\
nt \\
Tool \\
5 \\
\end{tabular} & \begin{tabular}{|c|} 
Perfor \\
Scor \\
e \\
(\%) \\
\end{tabular} & \begin{tabular}{|c|} 
imance \\
Assm \\
nt \\
Tool \\
6 \\
\end{tabular} & \begin{tabular}{|c|} 
\\
Scor \\
$e$ \\
$(\%)$
\end{tabular} & $\begin{array}{l}\text { Perf. } \\
\text { Comp. }\end{array}$ \\
\hline $\begin{array}{l}\text { 1. Convert any number between } \\
\text { different number systems. }\end{array}$ & \begin{tabular}{|l|}
$a$ \\
$b$ \\
\end{tabular} & $\begin{array}{l}1.1,1.2,1.3,1.4 \\
1.1,1,3,1.4 \\
\end{array}$ & HW\#1, & 96 & \begin{tabular}{|c|} 
Test \\
\#1. \\
Probl \\
1,2 \\
\end{tabular} & 80 & & & & & & & & & 3.5 \\
\hline $\begin{array}{l}\text { 2. Solve arithmetic operations using } \\
\text { binary, octal, and hexadecimal } \\
\text { numbers. }\end{array}$ & $\frac{a}{b}$ & $\begin{array}{l}1.1,1.2,1.3,1.4 \\
1.1,1.3,1.4 \\
\end{array}$ & - $\begin{array}{c}\text { HW'\#1. } \\
\text { Quest: } \\
5-6\end{array}$ & 99 & $\begin{aligned} H W W 2 . \\
Q s t: 2\end{aligned}$ & 89 & \begin{tabular}{|c|} 
Test \\
\#1. \\
Prob \\
3,4 \\
\end{tabular} & 80 & & & & & & & 3.6 \\
\hline $\begin{array}{l}\text { 3. Identify when radix and diminished } \\
\text { radix complements are to be used. }\end{array}$ & $\frac{a}{b}$ & $\frac{1.1,1.2,1.3,1.4}{1.1,1,3,1.4}$ & HW'\#2, & 89 & \begin{tabular}{|c|} 
Test \\
$\# 1$. \\
Probl5
\end{tabular} & 76 & & & & & & & & & 3.3 \\
\hline $\begin{array}{l}\text { 4. Describe the operation of each type } \\
\text { of basic logic gate. }\end{array}$ & $\begin{array}{ll}a \\
b \\
\end{array}$ & $\frac{1.1,1.2,1.3,1.4}{1.1,1.3,1.4}$ & $\begin{array}{c}H W \ldots 2 . \\
\text { Qst } 3\end{array}$ & 84 & \begin{tabular}{|c|} 
Test \\
$\# 1$. \\
Prob 6
\end{tabular} & 92 & \begin{tabular}{|c|} 
Test \\
$\# 2$. Q1
\end{tabular} & 66 & & & & & & & 3.2 \\
\hline $\begin{array}{l}\text { 5. Justify, prove and apply all } \\
\text { theorems of Boolean algebra. }\end{array}$ & a & $\frac{1.1,1.2,1.3,1.4}{1.1,1.3,1.4}$ & $\begin{array}{c}H W \# 2, \\
Q s t \\
5,6,7\end{array}$ & 90 & $\begin{array}{l}H W+\# 3 . \\
Q s t 2-6\end{array}$ & 74 & $\begin{array}{c}\text { Test } \\
\# 1 . \\
\text { Prob } 8\end{array}$ & 76 & $\begin{array}{l}\text { HW/ } 5 \\
\text { Prob } 7\end{array}$ & 72 & & & & & 3.1 \\
\hline $\begin{array}{l}\text { 6. Calculate gate level minimization } \\
\text { algebraically and with advanced } \\
\text { methods. }\end{array}$ & $\begin{array}{l}\mathrm{a} \\
\mathrm{b} \\
\mathrm{f}\end{array}$ & \begin{tabular}{|l|}
$1.1,1.2,1.3,1.4$ \\
$1.1,1.3,1.4$ \\
$1.1,1.2,1.3,1.4$ \\
\end{tabular} & $-\begin{array}{l}H W H 2, \\
Q s t \\
6,7\end{array} \mid$ & 87 & $\begin{array}{l}H W \# 3 . \\
\text { Qst 2-6 }\end{array}$ & 74 & $\begin{array}{c}\text { Test } \\
\# 1, \\
\text { Prob } 7\end{array}$ & 81 & $\begin{array}{c}\text { HW } 5 \\
\text { Prob } 7\end{array}$ & 72 & $\begin{array}{c}\text { Test } \\
\# 2 \mathrm{Q} 2\end{array}$ & 83 & & & 3.2 \\
\hline $\begin{array}{l}\text { 7. Describe and utilize each one of the } \\
\text { combinational logic devices. }\end{array}$ & $\frac{a}{b}$ & $\frac{1.1,1.2,1.3,1.4}{1.1,1.3,1.4}$ & $\begin{array}{c}\text { Test } \\
\# 2 \mathrm{Q} 3\end{array}$ & 73 & \begin{tabular}{|c|} 
Test \\
$\# 2$ Q5
\end{tabular} & 66 & \begin{tabular}{|c|} 
Test \\
$\# 2 Q 6$
\end{tabular} & 79 & & & & & & & 2.9 \\
\hline $\begin{array}{l}\text { 8. Design and optimize complex } \\
\text { combinational logic circuits. }\end{array}$ & $\begin{array}{l}a \\
b \\
d \\
h \\
\end{array}$ & \begin{tabular}{|c|}
$1.1,1.2,1.3,1.4$ \\
$1.1,1.3,1.4$ \\
$1.6,1.7$ \\
$1.1,1.2,1.3,1.4$ \\
$2.3,3.1$ \\
\end{tabular} & $\begin{array}{c}\text { HW\#6 } \\
\text { Qst: 5- } \\
10\end{array}$ & 60 & $\begin{array}{c}\text { Test } \\
\# 2 Q 4\end{array}$ & 66 & \begin{tabular}{|c|} 
Test \\
$\# 2 Q 7$
\end{tabular} & 72 & & & & & & & 2.7 \\
\hline $\begin{array}{l}\text { 9. Derive and utilize latches and flip- } \\
\text { flops. }\end{array}$ & $\begin{array}{l}a \\
b \\
d \\
h \\
\end{array}$ & \begin{tabular}{|c|}
$1.1,1.2,1.3,1.4$ \\
$1.1,1.3,1.4$ \\
$1.6,1.7$ \\
$1.1,1.2,1.3,1.4$ \\
$2.3,3.1$ \\
\end{tabular} & $H W \# 8$ & 80 & \begin{tabular}{|c|} 
Final \\
Projec \\
1
\end{tabular} & 88 & $\begin{array}{c}\text { Final } \\
\text { Exam. } \\
\text { Q1 }\end{array}$ & 74 & & & & & & & 3.2 \\
\hline $\begin{array}{l}\text { 10. Design and improve simple } \\
\text { synchronous sequential logic circuits. }\end{array}$ & $\begin{array}{l}a \\
b \\
d \\
f \\
h\end{array}$ & \begin{tabular}{|c|}
$1.1,1.2,1.3,1.4$ \\
$1.1,1.3,1.4$ \\
$1.6,1.7$ \\
$1.1,1.2,1.3,1.4$ \\
$2.3,3.1$ \\
\end{tabular} & Projec & 88 & \begin{tabular}{|c|} 
Final \\
Eam, \\
Q1
\end{tabular} & 74 & & & & & & & & & 3.2 \\
\hline
\end{tabular}

\section{Figure 1. Extract of instructor's evaluation in the standardized course evaluation form.}

\section{Course assessment metrics by an instructor}

This section explains the assessment metrics (or Assessment Tools as denoted in columns 4 through 15 in Figure 1) for each course objective. In a nutshell, a course evaluation is 
composed of various metrics measured by the two different class participants, the instructor and the students. Student input is explained in Section 4. All assessment metrics done by the instructor use traditional student work, such as homeworks, laboratories, quizzes, laboratories, projects, and exams (from now on denoted as "assignments"). This section, however, details a modified way to use assignment grades to better measure each course objective. As the grade of an assignment may not entirely reflect the various course learning objectives addressed in the assignment, all work required from the student is directly matched to a course learning objective. This has the added benefit of letting the student know the larger implication of working on a particular problem. As an example, a homework for the "Digital Circuits" class is shown in Figure 2. In each assignment, course learning objectives corresponding to each problem are indicated as shown in Figure 2. Thus, each problem is used to measure only the specified course learning objectives. For instance, Figure 2 shows problems 2 and 5 in HW\#1. Hence problems of \#2 and \#5 are used as a metric for course objectives "Convert any number between different number systems" and "Solve arithmetic operations using binary, octal, and hexadecimal numbers", respectively. All course objectives for this particular example are listed both in Figure 1 and in Appendix A. With this slight modification, course learning objectives can now be measured much more accurately. Note that it is not necessary to use all assignment problems as an assessment tool, but it is important to always specify course learning objective corresponding to a given problem. This has proven to provide the student a sense of ownership of the problem, thereby encouraging and motivating the student. Once the format is set for each homework, the instructor can change problems from year to year, however maintaining the corresponding related course learning objective. This way, the Excel spreadsheet need not be modified further.

\section{HOMEWORK \#1}

The next question(s) addresses the following course learning objective(s):

- $\quad$ Convert any number between different number systems.

2. Convert the following numbers with the indicated bases to decimal:

(a) $1212_{12}$

(b) $4310_{6}$

(c) 509

(d) $198_{11}$;

The next question(s) addresses the following course learning objective(s):

- $\quad$ Solve arithmetic operations using binary, octal, and hexadecimal numbers.

5. Add and multiply the following numbers without converting them to decimal.

(a) Binary numbers 1101 and 101.

(b) Hexadecimal numbers $1 \mathrm{E}$ and 23. Show all steps in this one. We may not cover this in class, but you can infer the method from doing multiplication either in binary or in decimal.

Figure 2. An example of homework to address each course objective

Another example is shown in Figure 3, this time a problem in Test 1. Two specified course objectives are given above test problem \#7, and thus problem \#7 is used to measure only the specified course objectives, "Justify, prove and apply all the theorems 
of Boolean Algebra", and "Calculate gate level minimization algebraically and with advanced methods."

\section{MIDTERM EXAM I}

THE NEXT QUESTION ADDRESSES THE FOLLOWING COURSE LEARNING OBJECTIVES:

Upon completion of this course, students will be able to:

- Justify, prove and apply all theorems of Boolean algebra.

- $\quad$ Calculate gate level minimization algebraically and with advanced methods.

7. (10 pts) Simplify the following function to a minimum number of literals using Boolean minimization. Show all necessary steps.

$\mathrm{F}(\mathrm{A}, \mathrm{B}, \mathrm{C}, \mathrm{D})=\mathrm{ABCD} \mathrm{D}^{\prime}+\left(\mathrm{A}+\mathrm{B}^{\prime}+\mathrm{D}\right)^{\prime}+(\mathrm{A}+\mathrm{B})(\mathrm{C}+\mathrm{D})\left(\mathrm{A}^{\prime} \mathrm{B}^{\prime}+\mathrm{C}^{\prime} \mathrm{D}^{\prime}\right)$

Figure 3. An example of exam to address each course objective

Any additional assignments given to students can be incorporated into the standardized course assessment for course objectives in Figure 1 as done with the examples in Figures 2 and 3. For example, one lab in "Circuit Analysis" class is shown in Figure 4 as a sample of measurement for an assessment tool because there is no lab in our Digital Circuit class. (There is a separate lab-based course, "Digital Hardware", used to complement the lecture-based Digital Circuits course) Hence, the given lab in Figure 4 can be used to measure only the course objectives specified in the lab document.

\section{LAB EXPERIMENT \#3}

This lab addresses the following course learning objective(s):

- Experience measuring equipment such as multimeter and power supply.

- Evaluate circuits using Ohm's law.

- Understand KCL and KVL laws.

Construct the following circuits on a breadboard and measure the each value given in tables with a multimeter. Verify all your measurements using theories you ....

\section{Figure 4. An example of lab to address each course objective}

An example of class project is shown in Figure 5. As before, the class project specifies the course objectives to be measured for the class.

\section{Class PROJECT}

This project addresses the following course learning objective:

- Design and optimize complex combinational logic circuits.

- $\quad$ Design and improve simple synchronous sequential logic circuits.

A digital controller is required to control a traffic light at the intersection of a busy, one-way main street and an occasionally used, one-way side street. ...

Figure 5. An example of project to address each course objective 


\section{Course assessment metrics by students}

All assessment tools mentioned so far involve assignments evaluated by the instructor. The complement of those measurements is the portion provided by students in each class through an end-of-term survey. The survey questions ask for the student perception on his or her achievement of a particular course learning objective. The survey is shown in Appendix D. Note that the survey is generated automatically by the Excel. The student survey is used as a metric as shown in Figure 6. Again, the class totals for all course learning objectives are normalized to a $0.0-4.0$ scale.

Character "E", "G", "A", "P", "N/A" in Figure 6 stand for "Excellent", "Good", "Average", "Poor", and "Not applicable", respectively, and are matched to the corresponding 4.0, 3.0, 2.0, 1.0, and 0.0 in the calculation of the students evaluation composite denoted by "Stud. Eval. Comp" in Figure 6. The GPA-like numbers on "Stud. Eval. Comp" are obtained by multiplying each point of E, G, A, P, and NA into student numbers who marked on corresponding boxes and averaging them. The last column, "Total Composite" in Figure 6 combines the performance composite (i.e. faculty evaluation) with the perception composite (student evaluation) though a simple average operation. The complete first page in the Excel spreadsheet is shown in Appendix A.

Excel sheets shown in Appendix B and D are obtained automatically using the data given on the first page. In particular, Appendix B shows that ABET criteria $\mathrm{a}-\mathrm{k}$ are converted into a GPA scale so that each ABET criterion can be mapped into a hard number. This number can be used in any way the Department decides to, for example, as a running comparison between similar classes from year to year. In brief, the numbers denoted by Course Objective Total Composite for each Educational Program Outcome in Appendix $\mathrm{B}$ are obtained by taking the average of the related course learning objectives. Then the scores for ABET a-k criteria on Appendix B are calculated by averaging the Composite column corresponding to relevant Educational Program Outcomes. The relationship has already been mentioned in Figure 1. It is worth noting that the usage of the data to do program-wide assessment is described in [1]. Also note that bar graphs for the class' contribution to each ABET criterion and program outcomes in Table 1 are plotted as shown in Appendix B.

Once again, all calculations (except for the inputting of raw data) are done automatically by macros embedded into the Excel spreadsheet all the way up to Appendix A, B, and D. The Appendix $\mathrm{C}$ presents basic class information. Just for full information of standardized assessment, all aforementioned 4 page Excel sheets are attached in Appendices. 


\begin{tabular}{|c|c|c|c|c|c|c|c|}
\hline \multirow[b]{3}{*}{ Course Objective } & & & & & & & \multirow[b]{3}{*}{$\begin{array}{c}\text { Total } \\
\text { Composite }\end{array}$} \\
\hline & \multicolumn{6}{|c|}{ Student Perception [ $\%$ ] } & \\
\hline & $\mathbf{E}$ & $\mathbf{G}$ & A & $\mathbf{P}$ & NA & $\begin{array}{l}\text { Stud } \\
\text { Eval. } \\
\text { Comp. } \\
\end{array}$ & \\
\hline $\begin{array}{l}\text { 1. Convert any number between } \\
\text { different number systems. }\end{array}$ & 15 & 9 & 1 & 1 & & 3.5 & 3.5 \\
\hline $\begin{array}{l}\text { 2. Solve arithmetic operations } \\
\text { using binary, octal, and } \\
\text { heradecimal numbers. }\end{array}$ & 16 & 8 & 2 & & & 3.5 & 3.6 \\
\hline $\begin{array}{l}\text { 3. Identify when radix and } \\
\text { diminished radix complements } \\
\text { are to be used. }\end{array}$ & 6 & 7 & 7 & 5 & 1 & 2.5 & 2.9 \\
\hline $\begin{array}{l}\text { 4. Describe the operation of } \\
\text { each type of basic logic gate. }\end{array}$ & 18 & 7 & 1 & & & 3.7 & 3.4 \\
\hline $\begin{array}{l}\text { 5. Justify, prove and apply all } \\
\text { theorems of Boolean algebra. }\end{array}$ & 11 & 14 & 1 & & & 3.4 & 3.3 \\
\hline $\begin{array}{l}\text { 6. Calculate gate level } \\
\text { minimization algebraically and } \\
\text { with advanced methods. }\end{array}$ & 13 & 9 & 2 & 2 & & 3.3 & 3.2 \\
\hline $\begin{array}{l}\text { 7. Describe and utilize each one } \\
\text { of the combinational logic } \\
\text { devices. }\end{array}$ & 7 & 11 & 6 & 2 & & 2.9 & 2.9 \\
\hline $\begin{array}{l}\text { 8. Design and optimize complex } \\
\text { combinational logic circuits. }\end{array}$ & 8 & 7 & 7 & 4 & & 2.7 & 2.7 \\
\hline $\begin{array}{l}\text { 9. Derive and utilize latches and } \\
\text { flip-flops. }\end{array}$ & 4 & 8 & 10 & 4 & & 2.5 & 2.8 \\
\hline $\begin{array}{l}\text { 10. Design and improve simple } \\
\text { synchronous sequential logic } \\
\text { circuits. }\end{array}$ & 6 & 6 & 9 & 5 & & 2.5 & 2.9 \\
\hline & & & & Num & er of & esponses & 26 \\
\hline
\end{tabular}

Figure 6. An example of students' evaluation addressing each course objective

\section{Conclusions}

This paper describes a method to obtain relevant data to assess ABET TAC criteria from a class, using an example of "Digital Circuits". The interconnection between each course learning objective, program educational outcome and ABET criteria is shown. Examples of various traditional course assessment tools are used to illustrate the potential to map a class' performance. The proposed course assessment is roughly divided into two parts: 
instructor's assessment and students' assessment. This assessment is done for each course learning objective. The data given by two parties is combined into a GPA-scale number. This numbers are further mapped into ABET criteria so that each ABET criteria can be measured in a GPA scale. Each assessment tool specifies clearly the course objectives addressed by each problem so that both students and instructor have a direct connection to the course learning objectives. The course assessment given in this paper is extended into all CET classes, and the data from all class was used to assess the CET program itself. The goal of making assessment more systematic was achieved by the proposed method in this paper. An interesting pedagogical investigation, left for future work, would be to evaluate how the proposed assessment can be correlated into real students' performance.

\section{Bibliography}

[1] E. Rodriguez-Marek, M.S. Koh, and C. Talarico, "Connecting the dots in assessment: From course student learning objectives to educational program outcomes to ABET assessment", in the Proc. of the 2008 ASEE annual Conf. and Exposition, Pittsburgh, PA, Jun. 2008

[2] R. M. Felder and R. Brent, "Designing and Teaching Courses to Satisfy the ABET Engineering Criteria", Journal of Engineering Education, 92 (1), pp. 7-25, Jan. 2003.

[3] H. Aaron and F. Meyer, "A direct assessment technique that works", in the Proc. of the 2007 ASEE annual Conf. and Exposition, Honolulu, HI, Jun. 2007

[4] S. Schreiner, J. Cezeaux, and D. Testa, "Faculty-friendly assessment systems for biomedical engineering programs", in the Proc. of the 2007 ASEE annual Conf. and Exposition, Honolulu, HI, Jun. 2007

[5] ABET TAC, "Criteria for accrediting engineering technology programs", ABET Inc. Nov. 2008

[6] Electrical and Computer Engineering Technology at Purdue university, "ECET Continuous Improvement Plan", http://www.purduecal.edu/ecet/cont_impr_plan.html

[7] Nasser Houshangi, "Curriculum assessment and enhancement at Purdue university calumet based on ABET 2000", ASEE Illinois-Indiana section conference, Apr. 2003 
Appendix A : First page of Excel sheet for the standardized course assessment

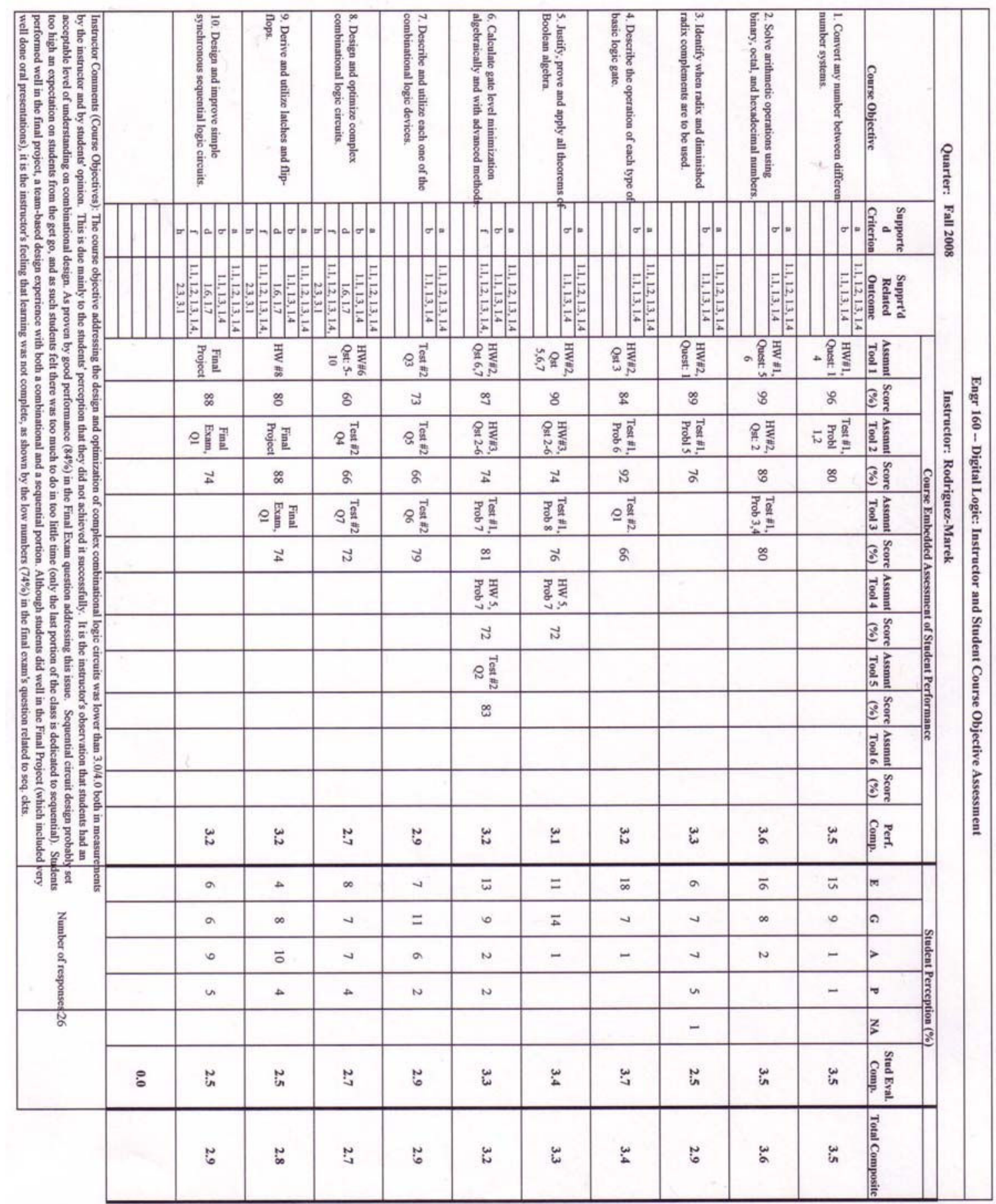


Appendix B : Second page of Excel sheet for the standardized course assessment
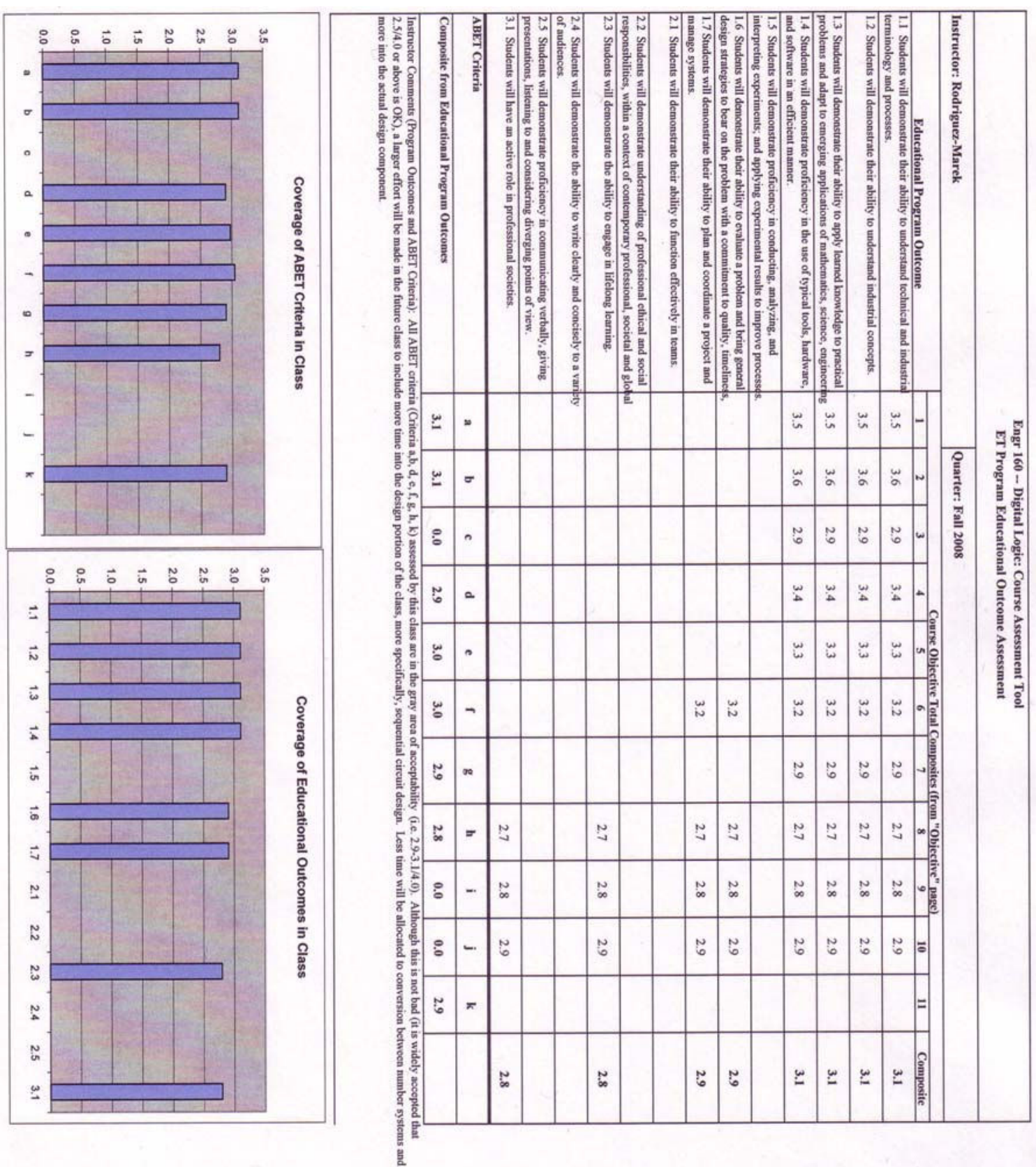

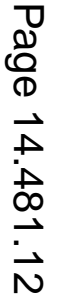


Appendix C : Third page of Excel sheet for the standardized course assessment

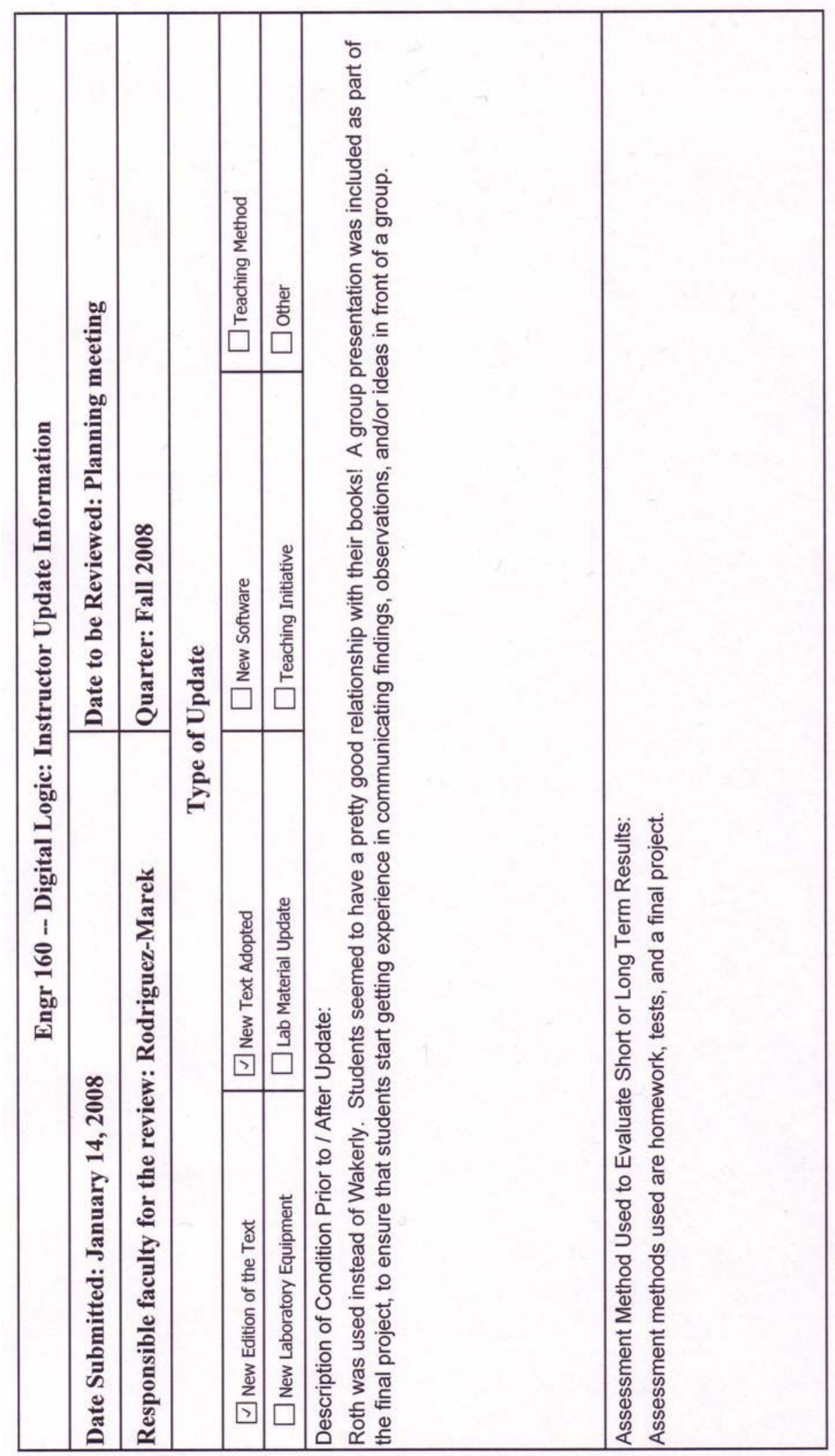

$$
\begin{aligned}
& \stackrel{0}{0} \\
& \stackrel{D}{D} \\
& \overrightarrow{\overrightarrow{+}} \\
& \dot{\vec{D}} \\
& \stackrel{\infty}{\vec{\omega}} \\
& \vec{\omega}
\end{aligned}
$$




\section{Appendix D : Fourth page of Excel sheet for the standardized course assessment}

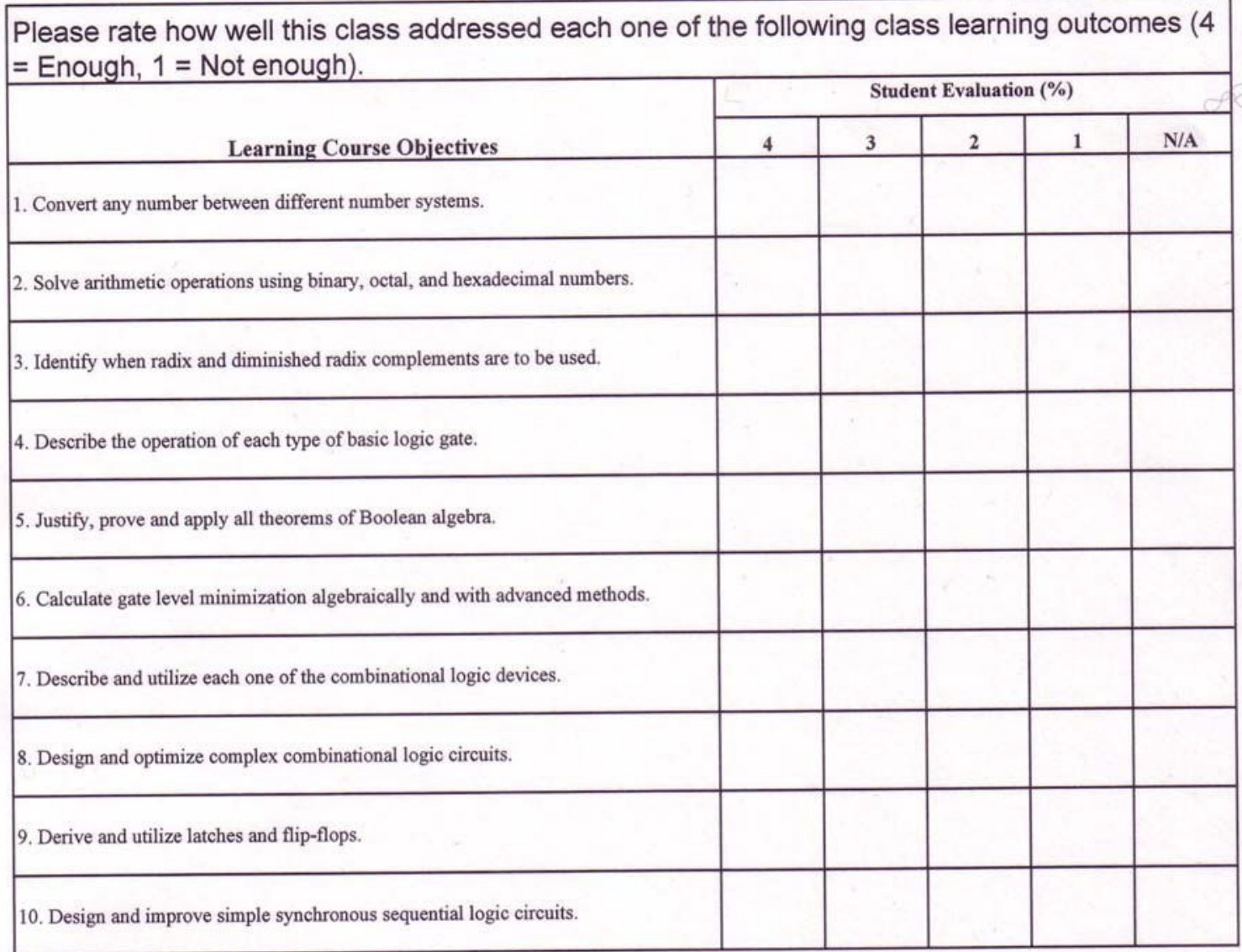

$$
\begin{aligned}
& \text { D } \\
& \stackrel{0}{0} \\
& \mathbb{D} \\
& \vec{D} \\
& \dot{\vec{D}} \\
& \stackrel{\infty}{\vec{D}} \\
& \vec{D}
\end{aligned}
$$

